\title{
A multidisciplinary approach to address climate-resilience, conservation and comfort in traditional architecture: The PROT3CT example
}

\author{
Negin Jahed $^{\mathrm{a}, \mathrm{b}}$, Sera Naz Ersoy ${ }^{\mathrm{a}}$, Nigel Griffiths ${ }^{\mathrm{c}}$, Ipek Gursel-Dino ${ }^{\mathrm{d}}$, Valentina Marincioni ${ }^{\mathrm{b}, \mathrm{e}}$, Ozgun \\ Ozcakir $^{\mathrm{a}, \mathrm{f}}$, Peter Rickaby ${ }^{\mathrm{b}, \mathrm{e}}$, Elif Sirt ${ }^{\mathrm{a}}$, Kai Wang ${ }^{\mathrm{g}}$, Sibel Yildirim-Esen ${ }^{\mathrm{a}}$, Tugce Yuruk ${ }^{\mathrm{a}}$, Guliz Bilgin- \\ Altinoz $^{\text {a*}}$, Yasemin D Aktas ${ }^{\mathrm{b}, \mathrm{g} *}$ \\ ${ }^{a}$ Conservation of Cultural Heritage, Middle East Technical University (METU), Ankara, Turkey ${ }^{b}$ UK Centre for Moisture in Buildings (UKCMB), London UK \\ ${ }^{c}$ Sustainable Traditional Buildings Alliance (STBA), London, UK ${ }^{d}$ Architecture, Middle East Technical University (METU), Ankara, Turkey \\ ${ }^{e}$ UCL Institute of Environmental Design \& Engineering, London UK \\ ${ }^{f}$ KORDER, Ankara, Turkey ${ }^{g}$ UCL Civil, Environmental and Geomatic Engineering, London UK \\ *corresponding authors: bilging@metu.edu.tr\&y.aktas@ucl.ac.uk
}

\begin{abstract}
Traditional dwellings despite their environmental credentials, due to age, previous damage, and residents unable to afford even the limited maintenance allowed by restrictive legal framework, may offer poor thermal performance, which is expected to be further exacerbated by changing climate. More than $70 \%$ of Turkey's built heritage stock is composed of traditional dwellings, which makes this stock able to create a major impact nationally on the building-related energy use, carbon emissions and population wellbeing. This research aims to develop an evidence-based multidisciplinary methodology for cost-effective retrofit of the traditional dwellings in Turkey, to improve energy performance, satisfy user expectations of comfort, and protect heritage value.

Peer-review under the responsibility of the organizing committee of the ICMB21.
\end{abstract}

Keywords: Traditional dwellings; energy-efficient retrofit; built heritage; Turkey; multisectoral; multidisciplinary

\section{Introduction}

The building stock is responsible for generating around $40 \%$ of overall emissions globally [1]. A large proportion of the building stock is composed of traditional buildings worldwide [2], which because of dilapidated condition due to age and previous damage, may demonstrate the poorest performance. This is more alarming in the case of traditional dwellings generally raised by low socioeconomic status families unable to apply regular maintenance, which are mostly left to their fate [3]. Taking into account that the consequences of the poor energy performance will be exacerbated by changing climate, improving energy performance in traditional buildings is an urge. In Turkey, traditional dwellings constitute more than $70 \%$ of the built heritage stock with listed status [4], making this set of buildings able to create a major impact nationally on the building-related energy use and carbon emissions and population wellbeing. PROT3CT project (http://prot3ct.metu.edu.tr) was set up in 2021 in partnership with UCL, METU, the Energy Efficiency Department of Ministry of Environment and Urbanization of Turkey, STBA, UKCMB, KORDER and SAYKA in order to identify the retrofit needs of traditional dwellings and develop an evidence-based methodological framework for cost-effective retrofit of the traditional dwellings in different climatic zones of Turkey, to improve energy performance, satisfy user expectations of comfort, and protect heritage value, and underpin related policies for Turkey.

Throughout this process, a wide-ranging investigation methods including field studies, surveys with target groups, hyghrothermal performance analysis, and building performance simulations are used while benefiting from the UK guidance and regulations in retrofit of traditional houses developed/contributed by members of UKCMB. By bringing a highly interdisciplinary and integrated research team together and engaging multi-sectoral partnership and key stakeholders of energy efficiency and heritage conservation including residents, local governments, universities and practitioners, we aim to bridge the gap between research and policy/practice.

\section{Project Structure}

The research is organised in four main workstreams divided into various tasks. The $1^{\text {st }}$ is the data collection and problem definition stage, aiming at detecting problems related to building fabric and indoor comfort level within the building. We engage with residents as the most immediate stakeholders of this project via open-ended resident surveys to ensure that their perspective and first-hand experience as the user are registered. To cover all local climate regions in Turkey, based on TS 825 climate classification, at least one representative city for each zone is selected, namely, Milas/Muğla (region 1, hot), Hatay/Antioch (region 1, hot), Kemerköy/Manisa (region 2, moderate), Güdül/Ankara (region 3, moderately cold), and Bitlis/Bitlis (region 4, cold). The case study buildings are selected from: i) houses that have preserved their authenticity and physical integrity, and ii) houses with residents that live permanently in the property. A detailed survey on architectural characteristics, construction system, materials, change and condition is carried out along with a diagnostic survey aimed at the primary agents of deterioration and moisture risk 


\section{ICMB21}

using non-destructive methods and risk assessment techniques. Each case study building is also environmentally monitored for at least 12 months with the aim of hygrothermal performance characterisation. The $2^{\text {nd }}$ work stream is the stage of analysis of collected data and developing pre-retrofit building performance simulation models according to the identified common damage mechanisms, recurrent issues raised by the residents, and analysis of past weather data, with the aim of quantification of performance gap. Prior to developing retrofit scenarios, viable measures are consulted with conservation experts in Turkey through expert inquiry to ascertain their compatibility with heritage values of buildings. Considering the cost-effectiveness of measures, various retrofitting scenarios, modified user behaviour, and different occupancy scenarios are then integrated into the building performance simulation models to analyse and identify the most suitable retrofit methods. To uncover the potential unintended consequences of proposed retrofit measures, like moisture risk, retrofit impact assessment is conducted at the end. The research work is complemented through $4^{\text {th }}$ work stream with producing educational/training material and a public stakeholder dialogue report within a range of stakeholders including academics, practitioners, communities and policymakers along with concept notes for research and innovation projects targeting overarching goals applicable to both Turkey and the UK.

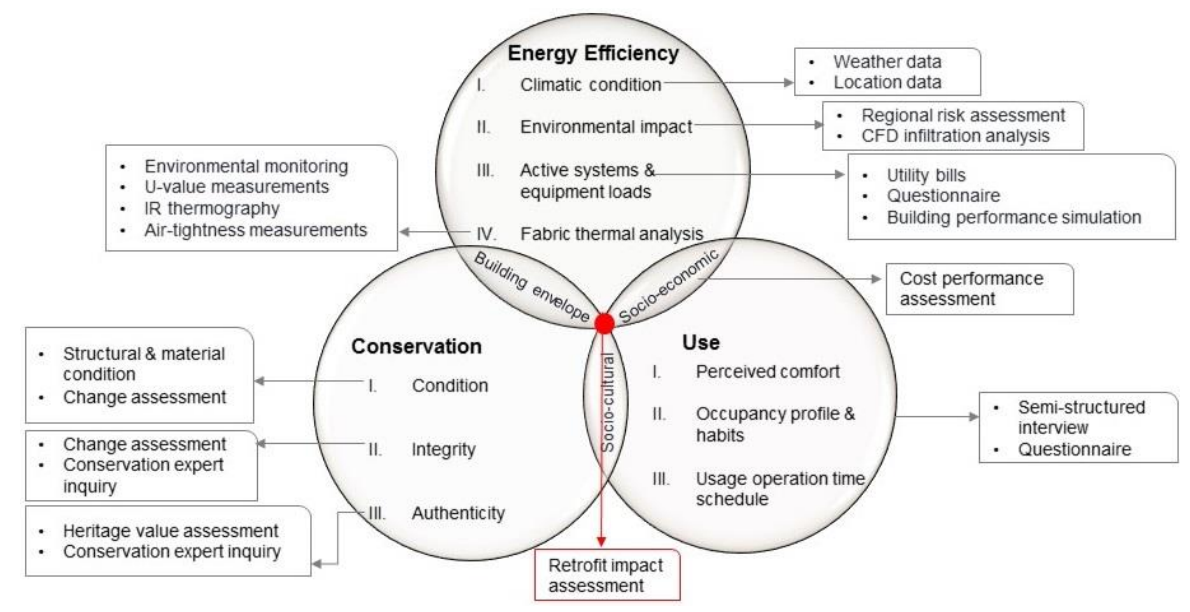

Figure 1. PROT3CT Conceptual Framework

\section{Discussion and Conclusion}

The retrofit of traditional buildings entails more challenges and risks than other buildings due to conservation requirements, the limited availability of reliable information on the building fabric, variability of traditional materials used, its complex heat and moisture behaviour [6] and the exemption of these buildings from policies and regulatory frameworks on buildings' energy use reduction [3]. PROT3CT addresses these challenges beyond the realm of a single discipline, which begs the need for a highly cross-disciplinary interactions from different backgrounds. Therefore, this research establishes new and sustainable research and innovation links through a highly interdisciplinary and multi-sectoral team with academic (METU and UCL teams, encompassing expertise in, among others, structural and conservation engineering, conservation architecture, urban and building physics, sociology, heritage economics and climate risk resiliency) and not-for-profit (KORDER, STBA and UKCMB) groups from Turkey and the UK, as well as organizations specializing on training and guidance development (STBA and UKCMB) and a key policy institution (Turkish Ministry of Environment and Urbanization). As such and through multiple qualitative and quantitative analysis methods PROT3CT aims to enhance our understanding of the highly complex and dynamic set of interactions between building performance, human experience and values that shape a heritage setting. It also offers significant value from a governance/policy point of view as it will provide a robust starting point for a national retrofit guidance framework for heritage buildings in Turkey which is currently almost entirely non-existent.

\section{Funding}

PROT3CT is jointly funded by British Council (no. 527666821) and TUBITAK (no. 119N514) through Newton Funds Institutional Links. We are grateful to the funding bodies.

\section{References}

[1] UNEP. (2020). 2020 Global status report for buildings and construction: Towards a zero-emission, efficient and resilient buildings and construction sector. United Nations Environment Programme (UNEP)

[2] Gori, V., Marincioni, V. and Altamirano-Medina, H. (2021). Retrofitting traditional buildings: a risk-management framework integrating energy and moisture. Buildings and Cities, 2(1), pp.411-424.

[3] Jahed, N.; Aktaş, Y.D.; Rickaby, P.; Bilgin Altınöz, A.G. Policy Framework for Energy Retrofitting of Built Heritage: A Critical Comparison of UK and Turkey. Atmosphere 2020, 11, 674. https://doi.org/10.3390/atmos11060674

[4] KVMGM. 2019. Available online: https://kvmgm.ktb.gov.tr/TR-44798/turkiye-geneli-korunmasi-gerekli-tasinmaz-kultur-varlig-.html

[5] Giorgi, F. \& Lionello, P. (2008) Climate change projections for the Mediterranean region, Glob. Planet. Chang. 63 (2008) 90-104, https://doi.org/10.1016/j.gloplacha. 2007.09.005.

[6] Akkurt, G. G., et al. (2020). Dynamic thermal and hygrometric simulation of historical buildings: Critical factors and possible solutions. Renewable\&Sustainable Energy Reviews, 118, 109509, https://doi. org/10.1016/j.rser.2019.109509 